\title{
Study of the Chinese Linguistics and Literatures Teaching Mode under New Curriculum
}

\author{
Li Feng-yun ${ }^{1, a}$ \\ ${ }^{1}$ Linyi University, Linyi,Shandong,276000,China \\ afeng_lfy@163.com
}

Keywords: curriculum reform Chinese Linguistics and Literatures teaching mode

\begin{abstract}
For the problems exit in today's Chinese Linguistics and Literatures teaching such as ignorance to the students' humanistic quality cultivation, ineffective teaching and the lack of effectiveness teaching evaluation system, this essay present the necessity of optimizing the teaching under new curriculum and put forward new methods to perfect its teaching mode, namely to explore the class teaching efficiency, strengthen the humanistic quality cultivation and emphasize the teaching evaluation system developing.

China's new round of curriculum reform has deeply changed the mode of basic education. Chinese Linguistics and Literatures, an important component of Chinese teaching, which play a significant $\mathrm{r}$ ole in students' humanistic quality and comprehensive abilities developing, undergone magnificent changes in teaching mode under the new curriculum reform. The imperfect teaching mode confronts lots of problems and challenges in the reforming background, how to optimize really counts.
\end{abstract}

\section{Problems exit in Chinese Linguistics and Literatures teaching mode}

A Ignorance to students' humanistic quality cultivation

As a basic principle of obtaining words information, the learning process of Chinese plays a particular role in students' character developing that cannot be replaced by any other subjects. However, in the teaching process, its significance to humanistic cultivation has been ignored and the training direction neglected. For today's students, learning Chinese is not only understanding and comprehending the words but actually the spiritual and humanistic connotation.

In the current education environment, they should equip themselves with professional cultural kn owledge as well as moral qualities, which is crucial in today's society measuring one's characters a nd more importantly impacting China's universal humanistic quality [1].

Chinese programs are gradually launched by several influential television stations in recently yea rs, formulating a Mandarin fever and expanding the international impact of China's characters to so me extent. According to incomplete survey, American enthusiasm for China Chinese characters gra dually increased, the survey results as shown in figure 1.

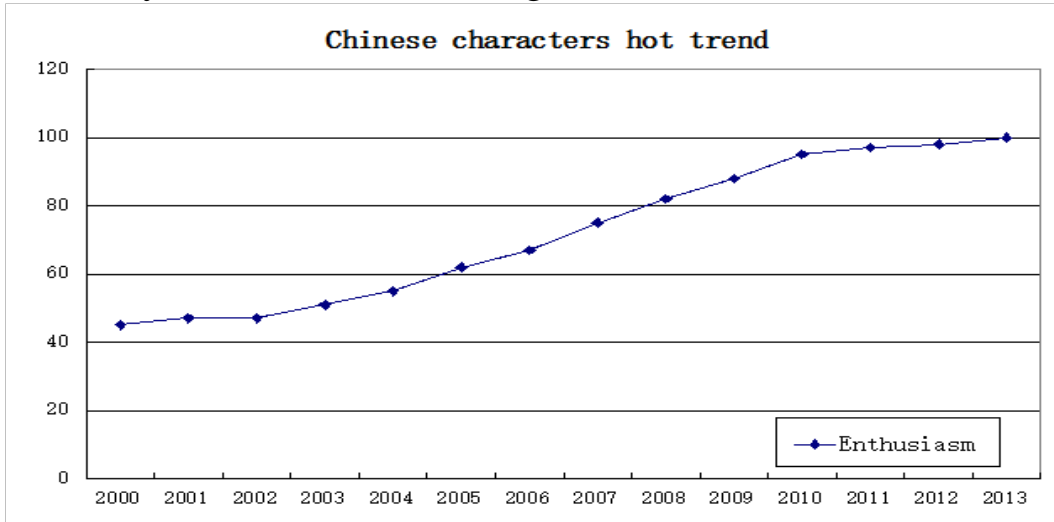

Fig. 1: Schematic diagram of hot trend Chinese characters

But what cannot be neglected is the devaluation to Chinese teaching and the decrease in student s' humanistic quality, that some provinces even decreased the teaching proportion of Chinese Lingu istics and Literatures. 
Therefore, as an important part of Chinese teaching, the Chinese Linguistics and Literatures shou ld equip students with the ability to understand the works and good-natured humanistic equality.

\section{$B$ The ineffective teaching of Chinese Linguistics and Literatures}

The Chinese Linguistics and Literatures, an integral part of Chinese teaching, the dissemination carrier of knowledge, can be a success only when students can largely digest the knowledge taught by the teachers. It can be said that the lesson's expected effect asks for the joint efforts of students and teachers.

With the development of China's education reform, the Chinese Linguistics and Literatures has a lso stepped into the new curriculum area. The great improvement and innovation cannot balance the old-fashioned, ineffective teaching mode.

The low efficiency of teaching has long been a big flaw of Chinese Linguistics and Literatures te aching, not only effect students learning but also waste teaching resources.

Teachers, the main subject of class, have worked long to improved efficiency which could only b een obtained by stimulating students' activeness. Take the Han-dynasty Yuefu poetry the Bride of Ji ao Zhongqing as an example, teachers, as the guide, should firstly teach the students the most effect ive way to learn these kinds of articles to help them master it in the shortest time.

\section{$C$ The absence of efficiency of the teaching evaluation system}

The teaching evaluation system, an important component of the Chinese Linguistics and Literatu res teaching, is the criterion to measure the teaching. But due to the incomplete development of the $t$ eaching mode, problems now come.

In the questions settled to strengthen the learning effect, the objective items are taking an increas ing proportion, presenting a simple direction of problem setting. The following statistical proportion according to the related questions of Chinese language and Literature Teaching of the provinces.

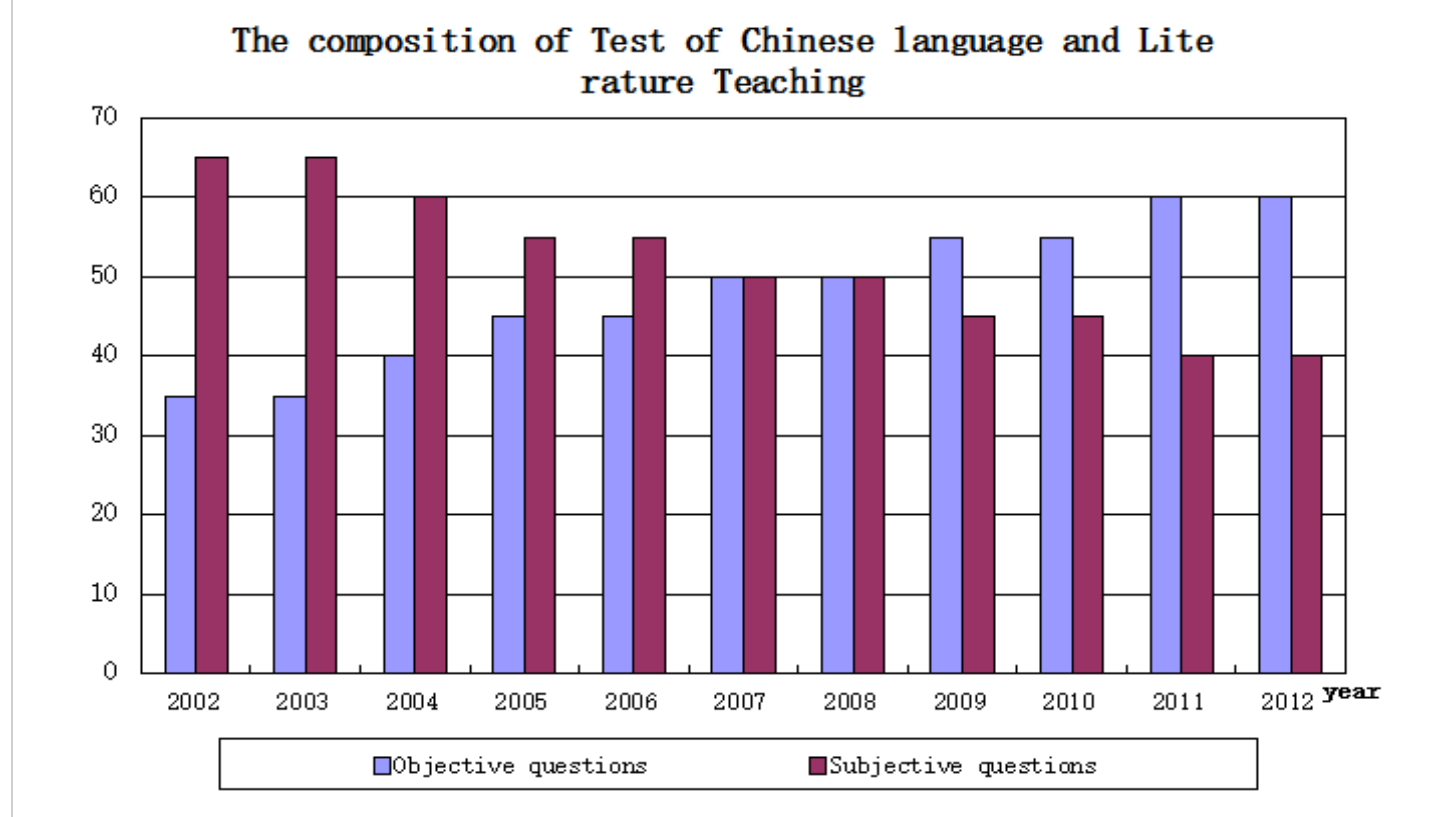

Fig. 2: The composition of Test of Chinese language and Literature Teaching

And for those subjective ones, with teachers paying too much attention to the reference answers, restricting the students' envision abilities, doing little good to the long-term development and hinde ring the play of comprehensive abilities.

Lots of teachers do not take the evaluation system seriously due to its incompleteness. And witho ut the fully combination with their own interests, deviation is normal in the teaching effects. 


\section{The necessity of optimizing the Chinese Linguistics and Literatures teaching}

\section{A Chinese Linguistics and Literatures is the necessary way to develop other disciplines}

The Chinese Linguistics and Literatures is a basic discipline to enhance the students' literary background and to enrich their association strength compared with other disciplines, which can only be empty talks without the former, the essence to extent.

It is especially significant concerning the ancient Chinese art, say the Life along the Bian River at the Pure Brightness Festival. And without the basis of discipline, understanding the inscriptions o $\mathrm{n}$ the Portrait of Flower-wearing Maids is impossible, not to mention the origins and rich knowledg e of the ancient painting. And lessons such as Chinese pictorial art are all equipped with the Chinese Linguistics and Literatures teaching to deepen other courses.

Only with basic knowledge of Chinese linguistics that we are able to extend ourselves into other disciplines to fully play our abilities.

Moreover, being literate or not closely related to our daily life as clearly expressing an idea asks for a sound basis in Chinese language or you would only have insipid and empty words. This is cru cial to graduates coming for employment as an abundant language is one of the key points deciding the results in the interview.

Thus the significance of Chinese Linguistics and Literatures not only reflected in school but eve ry corner of life. As the basic course of education, it is essential for other disciplines [3].

\section{B Chinese Linguistics and Literatures meets the demand to innovational talents}

The Chinese Linguistics and Literatures, with rich theory basis, is inevitable for China's education. With the increasing competition pressure and demand for talents, it is essential that the course develops more elites under the new curriculum.

This is a process of inheriting and developing, abandoning conventional malpractices and at the $s$ ame time innovating itself.

Under the new curriculum, the most obvious reform to the course is to meet the demands of talen ts. In the twenty-first century, a century that calls for innovative developing, only those nations that equipped with advanced innovation that are possible to promote its comprehensive developing, and it has become China's developing driving force.

A well qualified creative country need to broaden its talents cultivation, and as a part of China's education, the course plays a key point in the process [4]. Being the energy to innovative talents' cu ltivation, the reform can make significant contribution to China's education.

\section{Chinese Linguistics and Literatures promote the students' innovative abilities}

Innovation is the driving force of a nation's continuous development, the requirement of the age and one of the directions of China's students cultivating. In the conventional chalk and talk mode, students learn what the teachers told them and under their pressures, failing to improve students' enthusiasm and forming a kind of reliant mind which is unfavorable to their long-term developing[5].

The reform, however, fills the blank to a large extent. Aim to improve students' innovation ability, the reform pay a lot attention to it by holding oral defense regularly for example. When conveying their ideas, students form a figurative words expression, a process of innovation essentially. In the process of expressing his or her ideas with languages and words, a random and free combination, students get rid of the restriction from teachers, which counts a lot in improving their own innovative abilities. 


\section{New methods to perfect the Chinese Linguistics and Languages teaching mode}

\section{A To study the teaching efficiency in the class}

Efficiency is the key to the Chinese Linguistics and Languages teaching, which should be studie $\mathrm{d}$ under the new curriculum. In the conventional teaching mode, monopolylogue teachers had great stress and the long developing of it shows that it seriously hindered the improving of teaching effici ency. So how to improve it counts a lot in improving teaching quality and promoting long-term dev elopment.

Interactive communication between teachers and students in class is one of the ways to improve the efficiency. Take the Han-dynasty Yuefu poetry the Bride of Jiao Zhongqing as an example, by g iving students the initiative of guessing the meaning, leading them to understand it and digging dee per after reading the poetry, teachers can then give them three divergent questions to form the intera ctive teaching method. By questioning and answering, this arouse both teachers' and students' enth usiasm and thus improve the efficiency.

\section{B To strengthen the students' humanistic quality cultivation}

In present China's education system, the teaching of Chinese Linguistics and Literatures should not only focus on the words but also the cultivation of their humanistic quality to help students sho w more humanistic concern when mastering the linguistics.

Humanistic education mainly refers to students' ideological and ethical standards cultivating and developing, and that is essential to students, the main force of the community developing, along wit $\mathrm{h}$ abundant culture knowledge.

In the teaching, it is the culture connotation that should be emphasized, passing humanistic qualit y to the students. For instance, when interpreting Sima Qian's verse “once fly, fly up to the sky; onc e sing, sing high", students should not only understand the meaning, but also the connotation, the in spiration spirit from Sima Qian to keep reminding themselves to study hard and optimistic.

Only with the connotation, students can then formulate their own humanistic quality.

\section{To emphasize the teaching evaluation system developing}

The teaching evaluation system, an indispensible part of education, directly determines the proce ss of Chinese Linguistics and Literatures teaching with its completeness. For one thing, the target sh ould be clarified to have comprehensive reform to the examination system transforming the directio $\mathrm{n}$ from exmiantion-orientied to quality-oriented.

For another, diversified assessment method can be applied to the structural examination as basica lly checking professional knowledge while use academy credit system on the extra-curriculum ones. Perfecting teaching evaluation system by reforming the examination counts a lot to the developmen t of the teaching case.

It is not only better for the students' initiative and activeness, but also helps them to fully realize their potential. Therefore, the teaching evaluation system should have integral tradeoffs of the teach ers and students real situation to maximize its function.

\section{Conclusion}

All in all, during the developing process of Chinese Linguistics and Literatures teaching mode, teachers, as the guide of education, should teach students culture knowledge and cultivate their humanistic education as well, which formulate a benign learning atmosphere with innovative thinking and then promote the course's reform and developing.

\section{References}

[1] Gomila,T.,Calvo,P.Directions for An Embodied Cognitive Science:Toward An Integrated Appr oach. Handbook of cognitive science:An embodied approach . 2008 
[2] Howard Nicholas, Wan Ng. Factors Influencing the Uptake of A Mechatronics Curriculum Initi ative in Five Australian Secondary Schools [J]. International Journal of Technology and Design Education . 2012 (1)

[3] Ida Liseckiene, Irena Miseviciene, Mindaugas Dudonis.Organizational Changes in the Course of the PHC Reform in Lithuania from 1994 to 2010[J]. Health policy . 2012 (3)

[4] Elizabeth A. Jacobs, Lisa C. Diamond, Lisa Stevak. The Importance of Teaching Clinicians Wh en and How to Work with Interpreters[J]. Patient Education and Counseling. 2009 (2)

[5] Mary Bruce.States Unveil'’Common Core State Standards'’for Public Schools. http://abc-news. go. com/Politics/mational-school-standards-states-recommended/story? Id=10809243\&.page=2 .2010 